\title{
Fitness Consequences of Reciprocally Asymmetric Hybridization Between Simultaneous Hermaphrodites
}

\author{
Amporn Wiwegweaw, Keiichi Seki ${ }^{\dagger}$, Hiroki Utsuno and Takahiro Asami*
}

\author{
Department of Biology, Shinshu University, Matsumoto 390-8621, Japan
}

\begin{abstract}
Depending on fitness consequences, hybridization may rescue inbred populations; generate premating barriers, reproductive interference, or hybrid species; or extinguish a species. However, the fitness of hybrids is unpredictable without direct quantification of their performance in fitness components across multiple generations. The land snails Bradybaena pellucida and B. similaris, which are indigenous and non-indigenous in Japan, respectively, copulate with each other simultaneously and reciprocally. However, only $B$. pellucida produces hybrids, because it ends mating by removing the penis before transferring a spermatophore, while $B$. similaris inseminates $B$. pellucida. To evaluate the strength of an intrinsic postzygotic barrier against the hybrids produced by $B$. pellucida, we conducted breeding experiments in the laboratory and measured six life-history traits: (1) growth rate, (2) body weight at maturity, (3) number of days to first oviposition after being permitted to mate, (4) clutch size, (5) fecundity, and (6) hatchability. We also calculated the relative intrinsic fitness based on five of these trait values (excluding clutch size). $F_{1}$ hybrids exhibited heterosis in growth rate, body weight at maturity and relative intrinsic fitness. $F_{2}$ hybrids also showed heterosis in body weight at maturity. Nevertheless, the $F_{2}$ hybrids produced significantly fewer progeny than the mid-point value of the parental species. Thus, the $F_{2}$ hybrids exhibited weak outbreeding depression in reproduction, offsetting their vigor in body size. These results indicate that only a weak postzygotic barrier, contrasting with strong $F_{1}$ heterosis, has evolved during genetic divergence of the two sibling species in allopatry.
\end{abstract}

Key words: heterosis, outbreeding depression, reproductive isolation, postzygotic isolation, Pulmonata, Gastropoda

\section{INTRODUCTION}

Hybrids between species (or populations) are expected to exhibit generally lower fitness than the progeny of conspecific crosses, because of genetic divergence between the parental populations in allopatry (Mayr, 1963). Studies of interspecific hybrids have supported this traditional view of outbreeding depression (Coyne and Orr, 2004). Selection against hybrids may eliminate rare species (Levin et al., 1996), reinforce the evolution of premating isolation (Servedio and Noor, 2003), or generate reproductive interference (Gröning and Hochkirch, 2008). However, hybrids often show no detectable reduction or may even show an increase in fitness relative to the parental species (Arnold, 2006). Heterosis as a result of hybridization with immigrants could facilitate introgression of genetic resources, resulting in genetic rescue of an inbred population (Tallmon et al., 2004), fusion of divergent populations, or generation of new evolutionary lineages (Dowling and

\footnotetext{
* Corresponding author. Phone: +81-263-37-2494;

Fax : +81-263-37-2494;

E-mail: asami99@shinshu-u.ac.jp

${ }^{\dagger}$ Present address: Department of Biology, Toho University, Funabashi 274-8510, Japan

doi:10.2108/zsj.26.191
}

Secor, 1997; Mallet, 2005). Thus, explicit examination of hybrid fitness is crucial to elucidating the evolutionary consequences of hybridization. Most studies of hybrid fitness have, however, focused only on the first generation of hybrids (Coyne and Orr, 2004; Arnold, 2006). Hybrid breakdown may occur in later generations either because recombination breaks up parental coadapted gene complexes and/ or creates unfavorable genetic interactions (e.g., Edmands, 1999; Johansen-Morris and Latta, 2006) or through genetic incompatibility between the mitochondrial and nuclear genomes (Thulin and Tegelström, 2002). Thus, to understand the fitness consequences of hybridization, life-history traits that determine lifetime fitness should also be quantified in later generations.

Populations of terrestrial gastropods may be relatively easily isolated by distance because of limited dispersal abilities (e.g., Schilthuizen and Lombaerts, 1994; Pfenninger et al., 1996). Thus, the allopatric speciation model (Mayr, 1963) may be particularly applicable to speciation of land snails and slugs in general (Schilthuizen and Scott, 2003), and hybridization in the zone of secondary contact may have often played a critical role in the process of speciation. Quantification of hybrid performance in fitness components is, therefore, necessary to understand the mechanisms of speciation in these animals.

In terrestrial gastropods, only a few studies have directly 
examined the fitness consequences of hybridization, while many surveys of wild populations have found introgressive hybridization (e.g., Pinceel et al., 2005; Chiba, 2005). $F_{1}$ hybrids between the tree snails Partula mooreana and $P$. suturalis or $P$. mirabilis were anomalous in genital structure (Murray and Clarke, 1980). These are the only examples of outbreeding depression detected for interspecific hybrids in terrestrial gastropods. $F_{1}$ hybrids between conspecific populations exhibited reduced viability in the ground-dwelling snail Arianta arbustorum (Baur and Baur, 1992). Hybrid $F_{1}$ and $F_{2}$ offspring from crosses between subspecies of Helix aspersa were suggested to be inferior in growth or fecundity (Gomot-De Vaufleury and Borgo, 2001), although the results were not statistically consistent or validated. Populations of Cepaea nemoralis showed no detectable barrier to the production of viable $F_{1}$ or $F_{2}$ hybrids (Johnson et al., 1984). Similarly in freshwater pulmonates, only interspecific crosses in the genus Physa have shown sterility in $F_{1}$ hybrids (Dillon et al., 2007) and reproductive incompatibility (Dillon et al., 2004). Notably, no study has detected hybrid vigor or $\mathrm{F}_{2}$ breakdown in land or freshwater pulmonates, as far as we know. The paucity of direct quantification of hybrid fitness has probably resulted from the difficulties generally encountered in performing experimental crosses between related species, reflected also in the scarcity of studies even of premating barriers in pulmonates (Baur and Baur, 1992; Madec and Guiller, 1993; Fearnley, 1996; Rupp and Woolhouse, 1999; Dillon et al., 2007; Wiwegweaw et al., 2008).

We conducted breeding experiments to examine postzygotic isolation between sibling species of terrestrial pulmonates, Bradybaena pellucida and B. similaris. These hermaphroditic snails copulate simultaneously and reciprocally (Asami et al., 1993, 1997a; Seki et al., 2008). Bradybaena pellucida is endemic to Japan, whereas $B$. similaris was introduced presumably several hundred years ago (Komai and Emura, 1955; Asami et al., 1997b). They often occur sympatrically but may be negatively associated with each other in patchy distributions on a microsympatric scale (Seki et al., 2002). Although the two species mate assortatively with conspecifics, their premating isolation is incomplete under laboratory conditions.

Bradybaena similaris produces eggs only rarely as a result of copulation with $B$. pellucida, because the latter generally ends mating by removing the penis before transferring a spermatophore, while $B$. similaris inseminates $B$. pellucida, producing hybrids (Wiwegweaw et al., 2008). Thus, reciprocal asymmetry of hybridization results from mate discrimination between "male" $B$. pellucida and "female" $B$. similaris, but not from gametic incompatibility. The $F_{1}$ hybrids produced by $B$. pellucida hatch and grow to maturity (Seki et al., 2008). To understand the fitness consequences of hybridization, it is crucial to examine directly the relative performance of hybrids in survival and reproduction over multiple generations. Here we present the results of an examination of life-history traits of the two species and their hybrids over three generations.

\section{MATERIALS AND METHODS}

\section{Breeding}

We collected juveniles of $B$. pellucida and $B$. similaris from all- opatric populations in Tateyama, Chiba (34 $\left.55^{\prime} 22^{\prime \prime} \mathrm{N}, 139^{\circ} 52^{\prime} 8^{\prime \prime} \mathrm{E}\right)$

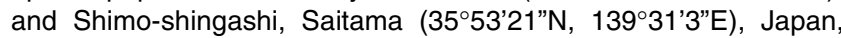
respectively. Our breeding experiments followed the protocol of Asami and Ohbayashi (1999) except as described below. We raised juveniles individually to maturity in plastic containers $(62 \times 50 \times 25$ $\mathrm{mm}$ ), and then randomly selected them to form 10 replicates each of 1) conspecific pairs of $B$. pellucida, 2) conspecific pairs of $B$. similaris, and 3) interspecific pairs. We first maintained each pair in a plastic container $(109 \times 79 \times 32 \mathrm{~mm})$ for 3 weeks to allow them to mate. For oviposition, we then separated each individual into a flowerpot (120 $\mathrm{mm}$ upper diameter/100 $\mathrm{mm}$ height) filled with sand and covered with a plastic plate, leaving a $30-\mathrm{mm}$ space beneath the lid. The pots and sand were sterilized before use. We collected eggs once a week for 2 months. For cases in which neither partner laid eggs for 1 month after separation of the pair, we placed them together for an additional 3 weeks to allow mating. We excluded from the analyses pairs that laid no eggs even after the second pairing. We fed the snails food composed of ground cat food, chicken egg shell, oat meal, and chlorella pills in a dry-weight ratio of $3: 4: 2: 1$. In the second generation, we bred 12 pairs of $F_{1}$ hybrids and 12 pairs of $F_{1}$ offspring of conspecific pairs for each species. In the third generation, we bred 12 pairs of $F_{2}$ hybrids obtained from pairs of $F_{1}$ hybrids and 12 pairs of $F_{2}$ offspring of conspecific pairs for each species. We raised 13 to 15 offspring obtained from each pair in the second and third generations. In every generation, we randomly paired virgin adults that were unrelated to each other.

\section{Fitness-component evaluation}

To evaluate major fitness components, we measured six lifehistory traits: 1 ) growth rate $(g)$, the slope of a simple linear regression of logarithm-transformed body weight on age after hatching; 2) maturation weight $(w)$, the body weight at maturity; 3) oviposition latency $(0)$, the number of days to the first oviposition after the 3week mating period; 4$)$ fecundity $(f)$, the number of eggs laid in the 2 months following the date of first oviposition; 5) clutch size; and 6 ) hatchability $(h)$, the arcsine-transformed ratio of hatching to nonhatching eggs. In the second and third generations, we measured individual body weights once a week from hatching to maturity, when the growth of the body whorl stopped. To obtain a single index that incorporates the contributions of these traits that may be relevant to survival and reproductive success, we calculated the relative intrinsic fitness (i) based on the five trait values (excluding clutch size, because this is probably roughly equivalent to fecundity in relation to reproductive success), as follows. We first calculated the individual fitness $(I)$ of each partner in the second and third generations as

$$
I=f g h w / o
$$

and then calculated the mean value for the partners in each pair. The relative intrinsic fitness (i) was then obtained by dividing the partner mean of each pair by the largest of the partner means among the three groups.

\section{Statistics}

In the first generation, an interspecific pair provided a single set of data on oviposition latency, fecundity, and hatchability for each of the two species, while a conspecific pair provided two sets of data for a single species. Therefore, for statistical analyses, we randomly selected one of the two sets of data from each conspecific pair and used it as an independent set of values for each pair. In the second and third generations, both partners of each pair were conspecifics or hybrids. Therefore, we pooled the two sets of data for each of the three variables from each pair and used the pooled data as an independent set of values for each pair. We found no significant deviation from a normal distribution for any of the six traits or relative intrinsic fitness for any of the three groups. Because we obtained data on the growth rate and maturation weight of each sibling, we 
employed nested one-way analysis of variance (ANOVA), and the Scheffé multiple comparison test when the ANOVA showed significant heterogeneity among the two species and their hybrids. For the other traits, we used one-way ANOVA and the Scheffé test for multiple comparisons, except for fecundity, which we compared by using analysis of covariance with body weight as a covariate. We compared the performance of the hybrids with the mean of the means of the two species by using the sign test.

\section{RESULTS}

In interspecific pairs, no $B$. similaris reproduced, but $80 \%$ of $B$. pellucida reproduced, while both species reproduced similarly in conspecific pairs (Table 1). In the first generation, there were no significant differences in fecundity among the three types of cross (four types of data), with the exception of $B$. similaris in interspecific crosses. Selfing in $B$. similaris typically results in a significant reduction in clutch size and hatchability (Ueshima and Asami, 2003; Asami and Asami, 2008). However, there was little heterogeneity among the three cross types in clutch size or hatching success, and $B$. similaris produced no eggs during the two-month period, indicating that it neither outcrossed nor selfed (Table 1). These results imply that $B$. pellucida, in interspecific pairs as well as conspecific pairs, reproduced by outcrossing, as Seki et al. (2008) demonstrated based on penial microsculpture, which in hybrids exhibits a form intermediate between the two species.

In the second generation, the hybrids grew faster than the two species, and $B$. similaris faster than $B$. pellucida (Fig. 1A; Table 1). At maturity, the hybrids were heavier than $B$. pellucida $(P<0.001)$ and $B$. similaris $(P<0.001)$, which did not differ significantly from each other $(P=0.152$; Fig. $2 A)$. Oviposition latency differed among the three groups and was shorter in the hybrid than in $B$. pellucida (Table 1). Clutch size of the hybrids was greater than that of $B$. similaris but did not quite differ significantly from that of $B$. pellucida $(\mathrm{P}=0.055)$. Simple linear regression analysis detected a significant correlation of body weight at maturity with fecundity in the hybrids $(P=0.002)$ but not in the two species ( $P=0.15$ for $B$. pellucida and 0.28 for $B$. similaris). Hybrid fecundity was greater than that of $B$. pellucida, but $B$. similaris performed better than both hybrids and $B$. pellucida (Table 1). Hatching rate did not differ significantly among the three groups (Table 1). The total number of hatchlings did not quite differ significantly among the three groups $(P=0.055)$ and the hybrids did not produce numbers significantly different from the mid-point of the two species $(P>0.90$; Fig. 3A). Relative intrinsic fitness differed among

Table 1. Reproductive performance of Bradybaena pellucida $(B P), B$. similaris $(B S)$, and their hybrids (Hyb). P1, probability in one-way ANOVA; P2, probability in sign test; P3, probability in ANCOVA; P4, probability in nested one-way ANOVA; $X$, difference between BP and BS; $Y$, difference between the hybrids and $B P ; Z$, difference between the hybrids and $B S$.

\begin{tabular}{|c|c|c|c|c|c|c|c|c|c|c|c|c|c|c|c|c|c|}
\hline \multirow{2}{*}{$\begin{array}{l}\text { Gener } \\
\text {-ation }\end{array}$} & \multirow{2}{*}{\multicolumn{2}{|c|}{ Cross type }} & \multirow{2}{*}{$\begin{array}{l}\text { No. } \\
\text { pairs }\end{array}$} & \multicolumn{4}{|c|}{ Ovipositing partners/pair } & \multirow{2}{*}{\multicolumn{2}{|c|}{$\begin{array}{l}\text { Oviposition } \\
\text { latency }\end{array}$}} & \multirow{2}{*}{$\mathrm{P} 1$} & \multirow{2}{*}{$\begin{array}{l}\text { Scheffé test } \\
\text { probability }\end{array}$} & \multirow{2}{*}{ P2 } & \multirow{2}{*}{\multicolumn{2}{|c|}{ Clutch size }} & \multirow{2}{*}{$\mathrm{P} 1$} & \multirow{2}{*}{$\begin{array}{c}\text { Scheffé test } \\
\text { probability }\end{array}$} & \multirow{2}{*}{$\mathrm{P} 1$} \\
\hline & & & & Sp. & Both & Either & None & & & & & & & & & & \\
\hline \multirow{4}{*}{1} & \multicolumn{2}{|c|}{$B P \times B P$} & 10 & $B P$ & 8 & 2 & 0 & \multicolumn{2}{|c|}{$22.13 \pm 6.13$} & & - & - & \multicolumn{2}{|c|}{$26.77 \pm 3.65$} & & - & - \\
\hline & \multirow{2}{*}{\multicolumn{2}{|c|}{$B P \times B S$}} & & $B P$ & 0 & 8 & 2 & \multirow{2}{*}{\multicolumn{2}{|c|}{$\begin{array}{c}30.88 \pm 7.08 \\
-\end{array}$}} & 71 & - & - & \multirow{2}{*}{\multicolumn{2}{|c|}{$\begin{array}{c}21.21 \pm 1.74 \\
0\end{array}$}} & & - & - \\
\hline & & & 10 & $B S$ & 0 & 0 & 2 & & & 0.71 & - & - & & & 0.28 & - & - \\
\hline & \multicolumn{2}{|c|}{$B S \times B S$} & 10 & $B S$ & 10 & 0 & 0 & \multicolumn{2}{|c|}{$21.70 \pm 4.73$} & & - & - & \multicolumn{2}{|c|}{$24.75 \pm 1.34$} & & - & - \\
\hline \multirow{3}{*}{2} & \multicolumn{2}{|c|}{$B P \mathrm{~F}_{1} \times B P \mathrm{~F}_{1}$} & 12 & $B P$ & 5 & 6 & 1 & \multicolumn{2}{|c|}{$42.40 \pm 8.65$} & & $X: 0.29$ & & \multicolumn{2}{|c|}{$49.07 \pm 1.61$} & & $X: 0.94$ & \\
\hline & \multirow{2}{*}{\multicolumn{2}{|c|}{$\begin{array}{c}\text { Hyb } F_{1} \times \text { Hyb } F_{1} \\
B S F_{1} \times B S F_{1}\end{array}$}} & 12 & Hyb $F_{1}$ & 8 & 4 & 0 & & $.25 \pm 4.05$ & 0.04 & Y: 0.043 & 0.07 & 61.68 & $8 \pm 3.81$ & 0.02 & Y: 0.055 & 0.29 \\
\hline & & & 12 & $B S$ & 12 & 0 & 0 & & $.50 \pm 4.39$ & & Z: 0.35 & & 50.7 & $5 \pm 2.40$ & & Z: 0.036 & \\
\hline & $B P F$ & $\mathrm{~F}_{2} \times B P \mathrm{~F}_{2}$ & 12 & $B P$ & 10 & 2 & 0 & & $.10 \pm 6.38$ & & - & & 48.1 & $7 \pm 2.23$ & & - & \\
\hline 3 & Hyb F & $\mathrm{F}_{2} \times \mathrm{Hyb}_{2}$ & 12 & $\mathrm{Hyb}_{2}$ & 7 & 5 & 0 & & $.57 \pm 8.03$ & 0.20 & - & 0.45 & 48.1 & $4 \pm 1.82$ & 0.68 & - & $>0.90$ \\
\hline & $B S F$ & $\mathrm{~F}_{2} \times B S \mathrm{~F}_{2}$ & 12 & $B S$ & 11 & 1 & 0 & & $82 \pm 4.22$ & & - & & $45.4 \varepsilon$ & $8 \pm 2.87$ & & - & \\
\hline & & $3 P \times B P$ & 34 & $B P$ & 23 & 10 & 1 & & & & & & & & & & \\
\hline Total & & $y b \times H y b$ & 24 & Hyb & 15 & 9 & 0 & & & & & & & & & & \\
\hline & & $B S \times B S$ & 34 & $B S$ & 33 & 1 & 0 & & & & & & & & & & \\
\hline Fecun & dity & P3 & $\begin{array}{r}\text { Scheffé } \\
\text { probab }\end{array}$ & $\begin{array}{l}\text { test } \\
\text { bility }\end{array}$ & $\mathrm{P} 2$ & $\begin{array}{r}\text { Hatch } \\
\text { rat }\end{array}$ & & P1 & $\log$ & $\begin{array}{l}\text { Growt } \\
\text { garithm }\end{array}$ & $\begin{array}{l}\text { h (slope after } \\
\text {-transformation) }\end{array}$ & & P4 & $\begin{array}{l}\text { Scheffé } \\
\text { probab }\end{array}$ & $\begin{array}{l}\text { test } \\
\text { ility }\end{array}$ & P2 & \\
\hline $57.00 \pm$ & 7.23 & & - & & - & $0.95 \pm 0$ & 0.015 & & - & & - & & - & - & & - & \\
\hline $48.50 \pm$ & 7.76 & 021 & - & & - & $0.92 \pm 0$ & .048 & 060 & - & & - & & - & - & & - & \\
\hline 0 & & 0.21 & - & & - & - & & 0.60 & - & & - & & - & - & & - & \\
\hline $69.90 \pm$ & 9.39 & & - & & - & $0.97 \pm 0$ & .021 & & - & & - & & - & - & & - & \\
\hline $83.20 \pm$ & 6.40 & & $X:<0.00$ & & & $0.96 \pm 0$ & .008 & & & & $89 \pm 0.009$ & & & $X:<0.0$ & & & \\
\hline $130.13 \pm$ & 17.13 & $<0.001$ & $Y: 0.01$ & & $>0.90$ & $0.94 \pm 0$ & .015 & 0.16 & 0.73 & & $00 \pm 0.008$ & & .001 & $Y:<0.0$ & & $<0.001$ & \\
\hline $170.50 \pm$ & 8.06 & & Z: 0.00 & & & $0.81 \pm 0$ & .064 & & & & $96 \pm 0.007$ & & & Z: 0.0 & & & \\
\hline $79.60 \pm$ & 10.80 & & $x:<0.00$ & & & $0.96 \pm 0$ & 0.009 & & & & $86 \pm 0.015$ & & & $X:<0.0$ & & & \\
\hline $74.57 \pm$ & 10.16 & $<0.001$ & Y: 0.97 & & 0.016 & $0.97 \pm 0$ & .008 & 0.070 & 0.45 & & $95 \pm 0.013$ & & .001 & $Y:<0.0$ & & 0.17 & \\
\hline $181.73 \pm$ & 15.68 & & $Z:<0.00$ & & & $0.94 \pm 0$ & .012 & & & & $00 \pm 0.008$ & & & $Z:<0.0$ & & & \\
\hline
\end{tabular}


A

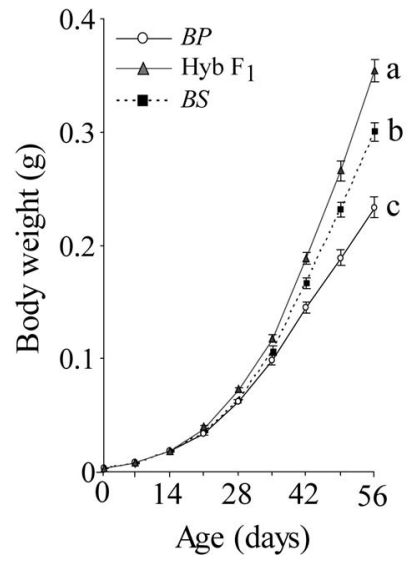

B

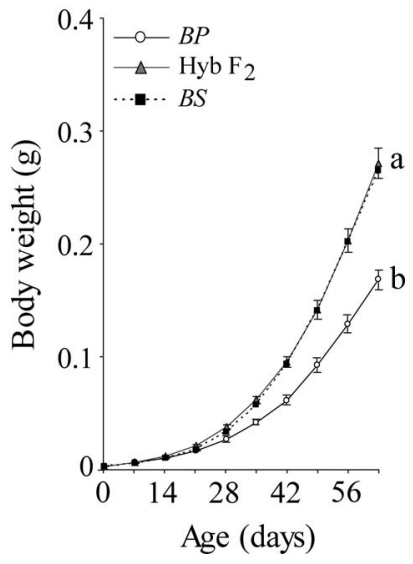

Fig. 1. Growth (mean \pm S.E.) in body weight in Bradybaena pellucida $(B P), B$. similaris $(B S)$, and their hybrids $(\mathrm{Hyb})$ in $(A)$ the second $\left(F_{1}\right)$ and $(B)$ the third $\left(F_{2}\right)$ generations. Different letters $(a, b$, C) indicate statistically significant differences.

A

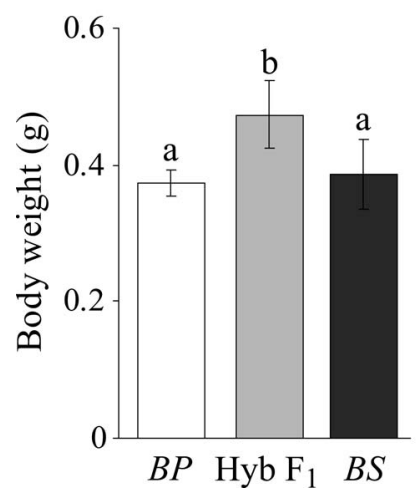

B

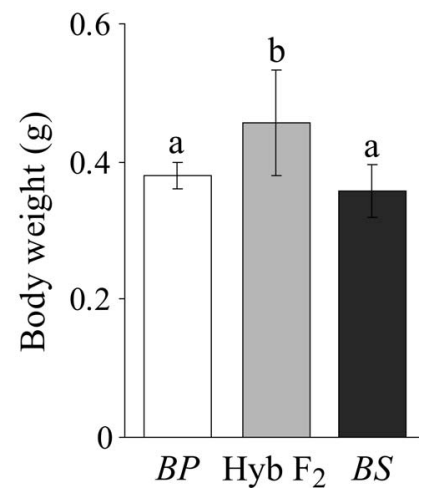

Fig. 2. Body weight at maturity (mean \pm S.E.) in Bradybaena pellucida $(B P), B$. similaris $(B S)$, and their hybrids $(\mathrm{Hyb})$ in $(A)$ the second $\left(F_{1}\right)$ and $(B)$ the third $\left(F_{2}\right)$ generations. Different letters $(a, b)$ indicate statistically significant differences.

the three groups $(\mathrm{P}=0.005$; Fig. 4A). Hybrids were superior to $B$. pellucida $(P=0.009)$ and $B$. similaris $(P=0.040)$, which did not differ from each other $(P=0.43)$.

In the third generation, $B$. similaris grew fastest, and the hybrids grew faster than $B$. pellucida (Fig. 1B, Table 1). The hybrids attained a larger body weight at maturity than $B$. pellucida $(P<0.001)$ and $B$. similaris $(P<0.001)$, but the two species did not differ significantly from each other $(P=0.143$; Fig. 2B). The three groups did not differ in oviposition latency (Table 1). None of the three groups showed a significant correlation between body weight at maturity and fecundity $(P=0.68$ for $B$. pellucida, 0.80 for $B$. similaris, and 0.70 for the hybrids) or a significant difference in clutch size (Table 1). Hybrids produced fewer eggs than the mid-point value of the two species, while $B$. similaris produced the largest number of eggs (Table 1). There were no significant differences in hatching success among the three groups, although the three groups produced different numbers of hatchlings $(P<0.001)$, with $B$. similaris producing more than

A

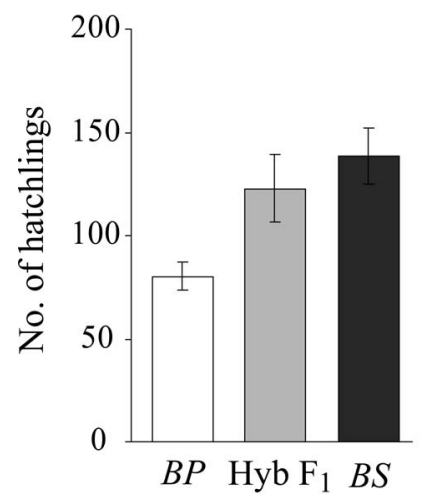

B

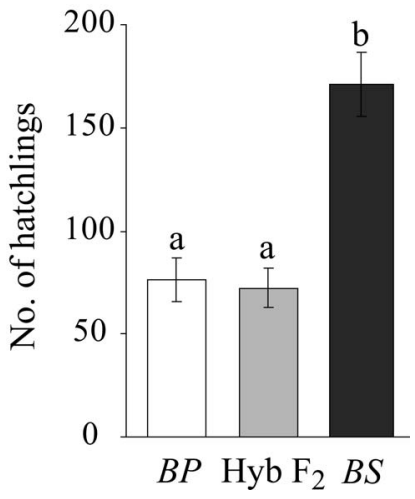

Fig. 3. Number of hatchlings (mean \pm S.E.) in Bradybaena pellucida $(B P), B$. similaris $(B S)$, and their hybrids $(\mathrm{Hyb})$ in $(\mathbf{A})$ the second $\left(F_{1}\right)$ and $(B)$ the third $\left(F_{2}\right)$ generations. Different letters $(a, b)$ indicate statistically significant differences.
A

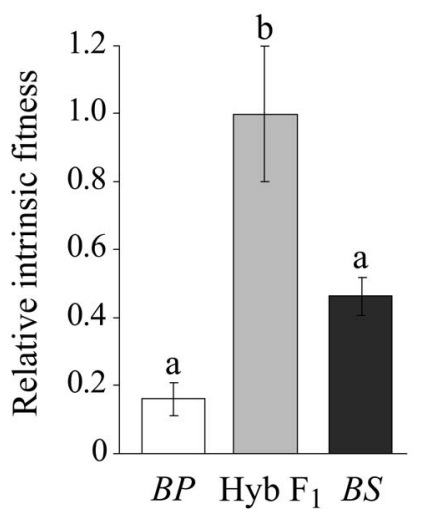

B

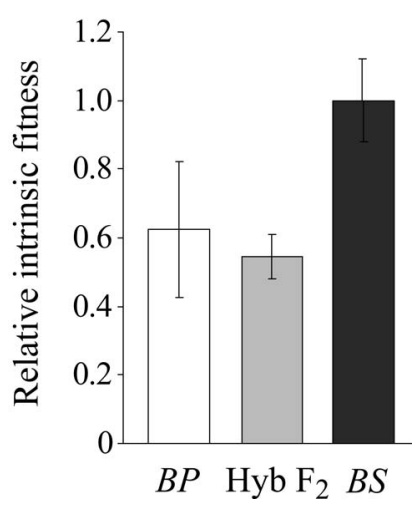

Fig. 4. Relative intrinsic fitness (mean \pm S.E.) based on the five life history traits in Bradybaena pellucida $(B P), B$. similaris $(B S)$, and their hybrids $(\mathrm{Hyb})$ in $(A)$ the second $\left(F_{1}\right)$ and $(B)$ the third $\left(F_{2}\right)$ generations. Different letters $(a, b)$ indicate statistically significant differences.

both the hybrids $(P<0.001)$ and $B$. pellucida $(P<0.001)$. The hybrids produced fewer viable progeny than the mid-point value of the two species $(P=0.016)$ and did not differ significantly from $B$. pellucida $(P=0.98$; Fig. 3B). The relative intrinsic fitness did not differ significantly among the groups (Fig. 4B).

\section{DISCUSSION}

\section{Hybrid vigor and breakdown}

The $F_{1}$ hybrids performed better than either of the two parental species in growth rate, body weight at maturity, and relative intrinsic fitness; that is, they exhibited heterosis. The $\mathrm{F}_{2}$ hybrids also achieved the heaviest body weight at maturity. However, the $F_{2}$ hybrids produced significantly fewer eggs and viable hatchlings than the mid-point value between the two species, and the heterosis exhibited by the $F_{1}$ hybrids in growth rate and relative intrinsic fitness disappeared. The superiority of the $F_{1}$ hybrids to either one of the two species in oviposition latency and clutch size was no 
longer detectable in the $F_{2}$ hybrids. Thus, the $F_{2}$ hybrids exhibit a weak breakdown in reproduction, offsetting their superior growth rate and body size at maturity, although their reproductive performance was not the worst statistically. Recombination may be responsible for the inferiority of $F_{2}$ hybrids compared with the vigor of $F_{1}$ hybrids. Because only $B$. pellucida provides the $F_{1}$ hybrids, possible maternal effects on the performance of the $F_{1}$ or $F_{2}$ hybrids are not testable, even though their quantitative traits may be affected in the present system as well as in Drosophila melanogaster (Gilchrist and Partridge, 1999).

Our experiment demonstrated intrinsic differences among the two species and their hybrids in life-history traits under standardized laboratory conditions. In the natural environment, differences in growth rate and body size could influence rates of survival against predators (e.g., Gittenberger, 1995) and desiccation (e.g., Asami, 1993). Also, the snails grew faster with the standard laboratory food and in relatively constant conditions than they would in the wild. To quantify realized lifetime fitness in natural habitats, the effects of these extrinsic factors need to be incorporated. However, the differences in fitness components demonstrated in the laboratory remain useful in estimating relative reproductive success, unless extrinsic factors affect it differentially through genotype-environment interactions. For example, fecundity of pulmonates often varies depending on the body size (Jordaens et al., 2007), although no effect of body weight at maturity on fecundity was detected over the 2-month duration of the experiment. Thus, relative intrinsic fitness, which incorporates the contribution of each trait as a component of lifetime fitness, is useful for examining relative differences in realized fitness under no genotype-environment interactions. It should be taken as a rough estimate, because the relative importance of each trait in shaping fitness could also vary depending on the environment.

\section{Reciprocal asymmetry of hybridization}

Pulmonates are simultaneous hermaphrodites and mate either reciprocally or non-reciprocally, depending on the species. Snails in the genus Bradybaena perform simultaneous reciprocal copulation in the face-to-face position, which is typical of groups with flat to globose shells (Asami et al., 1998; Davison and Mordan, 2007). However, the partners do not necessarily inseminate each other (Leonard, 2006). In our experiment, in all three generations, the proportion of pairs in which both partners reproduced by reciprocal mating was higher in $B$. similaris than in both $B$. pellucida ( $\mathrm{P}<0.003$ with Bonferroni correction) and the hybrids $(P<0.001)$. This may suggest that the conspecific partners interact with each other during simultaneous reciprocal copulation differently between the two species, and that normal interactions therefore fail during interspecific copulation. Such a behavioral incompatibility between the species may underlie the unidirectional hybridization in spite of simultaneous reciprocal copulation (Wiwegweaw et al., 2008).

In our allozyme survey at 12 loci across allopatric populations in Japan, the mean genetic distance between the two species $(0.238)$ was significantly larger than that within $B$. pellucida $(0.006)$ and that within $B$. similaris (0.008) (Seki et al., 2008). Bradybaena similaris was intro- duced and began to be sympatric with the indigenous species $B$. pellucida in Japan probably only a few hundred years ago. Thus, their evolutionary divergence must have proceeded mostly independently. Furthermore, the present study detected heterosis in the $F_{1}$ hybrids and only weak breakdown in the $F_{2}$ hybrids. Therefore, instead of reinforcement, genetic divergence in allopatry should be responsible for their asymmetric prezygotic reproductive isolation.

Although the inferiority of $\mathrm{F}_{2}$ hybrids indicates the effect of some postzygotic reproductive barrier, they do not suffer severe reduction in fertility or viability. Moreover, the chance of mating between two hybrids is probably limited in the wild, since the $F_{1}$ hybrids would be more likely to encounter $B$. pellucida or $B$. similaris. The two species are distinct in penial microsculpture, which may have a function in discrimination during copulation, and the $\mathrm{F}_{1}$ hybrids exhibit an intermediate microsculpture (Seki et al., 2008). If the $F_{1}$ hybrids are intermediate in traits for premating discrimination between the parental species, they may backcross more readily than the two species mate with each other, and genetic introgression should proceed unless ecological isolation or genetic incompatibility is in effect. Because only $B$. pellucida and not $B$. similaris produces hybrids, mtDNA may exhibit asymmetric introgression to $B$. similaris, although mtDNA could also leak in the opposite direction if backcrossing of the $F_{1}$ hybrids allows $B$. similaris to reproduce.

The two species primarily inhabit lowlands and are often associated with domestic or cultivated areas in suburbs (Seki et al., 2002). Thus, both species could have frequently been dispersed with humans and had chances to migrate between populations over the several hundred years since B. similaris was introduced (Komai and Emura, 1955; Asami et al., 1997b). In the wild, the two species can be relatively easily distinguished, because only $B$. pellucida displays a fluorescent yellow pigmentation in the dorsal mantle through the translucent shell (Seki et al., 2008). We have found morphologically intermediate individuals in several colonies in the Boso peninsula, Japan. However, the two species, which are defined by morphology, do not coexist within the same patches or show gradual changes in morphology between colonies of the two species in sympatry where their distributions overlap (Seki et al., 2002). Thus, at least at loci that are responsible for their morphological differences, introgression may not be proceeding rapidly toward genetic fusion or replacement between the two species.

No earlier study has quantified the fitness components of hybrids across three generations in terrestrial gastropods. We have demonstrated hybrid vigor in pulmonate gastropods for the first time, as well as the presence of only weak outbreeding depression after the secondary contact of sibling species of snails that had diverged in allopatry. Investigation of backcross success, ecological isolation, interspecific introgression, and phylogeny are important subjects for further studies to explore the evolutionary consequences of reciprocally asymmetric hybridization between the two species.

\section{ACKNOWLEDGMENTS}

We thank James Murray, Robert Cowie, and Angus Davison for critical comments, and Naoko Asami and Mao Asami for field collections. This study was supported by Grants-in-Aid from the 
Japan Society for the Promotion of Science to T.A. and a Hitachi Scholarship to A.W.

\section{REFERENCES}

Arnold ML (2006) Evolution Through Genetic Exchange. Oxford University Press, Oxford

Asami T (1993) Interspecific differences in the tolerance of desiccation by juvenile land snails. Funct Ecol 7: 571-577

Asami T, Asami N (2008) Maintenance mechanism of a supergene in the terrestrial pulmonate Bradybaena similaris. Basteria 72: $119-127$

Asami T, Ohbayashi K (1999) Effects of oviposition substrate on lifetime fecundity of the terrestrial pulmonate Bradybaena similaris. J Conchol 36: 1-9

Asami T, Fukuda H, Tomiyama K (1993) The inheritance of shell banding in the land snail Bradybaena pellucida. Venus 52: 155-159

Asami T, Ohbayashi K, Seki K (1997a) The inheritance of shell color in the land snail Bradybaena pellucida. Venus 56: 35-39

Asami T, Yamashita H, Park J, Ishikawa H (1997b) Geographical distribution of the land snail Bradybaena pellucida (Pulmonata: Bradybaenidae). Yuriyagai 5: 31-42

Asami T, Cowie RH, Ohbayashi K (1998) Evolution of mirror images by sexually asymmetric mating behavior in hermaphroditic snails. Am Nat 152: 225-236

Baur B, Baur A (1992) Reduced reproductive compatibility in the land snail Arianta arbustorum from distant populations. Heredity 69: 65-72

Chiba S (2005) Appearance of morphological novelty in a hybrid zone between two species of land snail. Evolution 59: 1712-1720

Coyne JA, Orr HA (2004) Speciation. Sinauer Associates, Sunderland

Davison A, Mordan P (2007) A literature database on the mating behavior of stylommatophoran land snails and slugs. Am Malacol Bull 23: 173-181

Dillon RT Jr, Earnhardt CE, Smith TP (2004) Reproductive isolation between Physa acuta and Physa gyrina in joint culture. Am Malacol Bull 19: 63-68

Dillon RT Jr, Robinson JD, Wethington AR (2007) Empirical estimates of reproductive isolation among the freshwater pulmonate snails Physa acuta, $P$. pomilia, and $P$. hendersoni. Malacologia 49: 283-292

Dowling TE, Secor CL (1997) The role of hybridization and introgression in the diversification of animals. Annu Rev Ecol Syst 28: $593-619$

Edmands S (1999) Heterosis and outbreeding depression in interpopulation crosses spanning a wide range of divergence. Evolution 53: 1757-1768

Fearnley RH (1996) Heterogenic copulatory behaviour produces non-random mating in laboratory trials in the land snail Helix aspersa Müller. J Mollus Stud 62: 159-164

Gilchrist AS, Partridge $L$ (1999) A comparison of the genetic basis of wing size divergence in three parallel body size clines of Drosophila melanogaster. Genetics 153: 1775-1787

Gittenberger E (1995) Adaptations of the aperture in terrestrial gastropod-pulmonate shells. Neth J Zool 46: 191-205

Gomot-De Vaufleury A, Borgo R (2001) Experimental hybridization between two sub-species of snails (Helix aspersa aspersa and Helix aspersa maxima): consequences for fertility, survival and growth. Invertebr Rep Dev 40: 217-226

Gröning J, Hochkirch A (2008) Reproductive interference between animal species. Q Rev Biol 83: 257-282
Johansen-Morris AD, Latta RG (2006) Fitness consequences of hybridization between ecotypes of Avena barbata: hybrid breakdown, hybrid vigor, and transgressive segregation. Evolution 60: 1585-1595

Johnson MS, Stine C, Murray J (1984) Reproductive compatibility despite large-scale genetic divergence in Cepaea nemoralis. Heredity 53: 655-665

Jordaens K, Dillen L, Backeljau T (2007) Effects of mating, breeding system and parasites on reproduction in hermaphrodites: pulmonate gastropods (Mollusca). Anim Biol 57: 137-195

Komai T, Emura S (1955) A study of population genetics of the polymorphic land snail Bradybaena similaris. Evolution 9: 400-418

Leonard JL (2006) Sexual selection: lessons from hermaphrodite mating systems. Integr Comp Biol 46: 349-367

Levin DA, Francisco-Ortega J, Jansen RK (1996) Hybridization and the extinction of rare plant species. Conserv Biol 10: 10-16

Madec L, Guiller A (1993) Observations on distal genitalia and mating activity in three conchologically distinct forms of the land snail Helix aspersa Müller. J Mollus Stud 59: 455-460

Mallet $J$ (2005) Hybridization as an invasion of the genome. Trends Ecol Evol 20: 229-237

Mayr E (1963) Animal Species and Evolution. Belknap Press, Cambridge, MA

Murray J, Clarke B (1980) The genus Partula on Moorea: speciation in progress. Proc $\mathrm{R}$ Soc Lond B 211: 83-117

Pfenninger M, Bahl A, Streit B (1996) Isolation by distance in a population of a small land snail Trochoidea geyeri: evidence from direct and indirect methods. Proc R Soc Lond B 263: $1211-1217$

Pinceel J, Jordaens K, Backeljau T (2005) Extreme mtDNA divergences in a terrestrial slug (Gastropoda, Pulmonata, Arionidae): accelerated evolution, allopatric divergence and secondary contact. J Evol Biol 18: 1264-1280

Rupp JC, Woolhouse MEJ (1999) Impact of geographical origin on mating behaviour in two species of Biomphalaria (Planorbidae: Gastropoda). Anim Behav 58: 1247-1251

Schilthuizen M, Lombaerts M (1994) Population structure and levels of gene flow in the Mediterranean land snail Albinaria corrugata (Pulmonata: Clausiliidae). Evolution 48: 577-586

Schilthuizen M, Scott BJ (2003) Allopatric speciation: not so simple after all. In "Evolution: from Molecules to Ecosystems" Ed by A Moya, E Font, Oxford University Press, Oxford, pp 173-181

Seki K, Inoue S, Asami T (2002) Geographical distributions of sibling species of land snails Bradybaena pellucida and $B$. similaris in the Boso peninsula. Venus 61: 41-48

Seki K, Wiwegweaw A, Asami T (2008) Fluorescent pigment distinguishes sibling species of snails. Zool Sci 25: 1212-1219

Servedio MR, Noor MAF (2003) The role of reinforcement in speciation: theory and data. Annu Rev Ecol Evol Syst 34: 339-364

Tallmon DA, Luikart G, Waples RS (2004) The alluring simplicity and complex reality of genetic rescue. Trends Ecol Evol 19: 489-496

Thulin C-G, Tegelström H (2002) Biased geographical distribution of mitochondrial DNA that passed the species barrier from mountain hares to brown hares (genus Lepus): an effect of genetic incompatibility and mating behaviour? J Zool 258: 299-306

Ueshima R, Asami T (2003) Single-gene speciation by left-right reversal. Nature 425: 679

Wiwegweaw A, Seki K, Mori H, Asami T (2008) Asymmetric reproductive isolation during simultaneous reciprocal mating in pulmonates. Biol Lett, DOI: 10.1098/rsbl.2008.0714 